\title{
Citizens' Perception about M-Government Services: Results from an Exploratory Survey
}

\author{
Nripendra P. Rana \\ Emerging Markets Research Centre \\ (EMaRC), School of Management \\ Swansea University Bay Campus \\ Fabian Way, Swansea, SA1 8EN, UK \\ Email: nrananp@gmail.com
}

\author{
Marijn Janssen \\ Faculty of Technology, Policy, \& \\ Management, Delft University of \\ Technology, Delft, The Netherlands \\ Email: M.F.W.H.A.Janssen@tudelft.nl
}

\author{
Ganesh P. Sahu \\ School of Management Sciences, \\ Motilal Nehru National Institute of \\ Technology Allahabad, India \\ Email: gsahu@mnnit.ac.in
}

\author{
Abdullah Baabdullah \\ Department of MIS, Faculty of Economics \& \\ Administration, King Abdulaziz University, Jeddah, Saudi \\ Arabia \\ Email: baabdullah@kau.edu.sa
}

\author{
Yogesh K. Dwivedi \\ Emerging Markets Research Centre (EMaRC), School of \\ Management, Swansea University Bay Campus \\ Fabian Way, Swansea, SA1 8EN, UK \\ Email: ykdwivedi@gmail.com
}

\begin{abstract}
The development of mobile technology is facilitating the transformation in a way that governments deliver their services. Mobile government is one area that has received very little research, but it can have a tremendous impact on the way citizens engage with their government. This research analyses the data gathered from 81 respondents through online survey on the various aspects of mobile government and collects their views on some of the key questions related to the use of mobile government. The findings showed that although citizens are aware of the possibilities they hardly used mobile devices as a direct communication channel with government. Most users tend to use social media platforms and social media is used as an intermediary between government and citizens. The findings of this research also indicated that although the users are well aware of m-government services and own smartphones, only a handful of them use their mobiles for accessing government services.
\end{abstract}

\section{Keywords}

m-government, social media, e-government, acceptance, adoption, awareness, citizens, India

\section{Introduction}

Over the last couple of decades, government across the world have been moving towards providing their citizens electronic services with varying degree of success [2]. In the last decade, some of the governments have realized the rapid evolution of wireless technologies and the ubiquity of Internet-enabled mobile devices across various countries.
This encouraged these governments to move naturally towards mobile government (hereafter, m-government) as a next step to improve their quality and delivery of their services. M-government is an additional value to the existing e-government services as citizens are able to access government services through mobile phones, Wi-Fi enabled devices over wireless networks [1]. Moreover, the high adoption of Internet-enabled mobile devices with over 2.6 billion users worldwide has exceeded the use of personal computers in many countries [2, 3]. By 2020, there will be 6.1 billion smartphone users globally led by enormous growth in less mature markets and this number will surpass the number of active fixed line subscriptions worldwide by that time [3].

With the increasing popularity of mobile communication devices, m-government services have become vital for improving user-to-government mobile communication. Despite all the benefits brought about by these devices, users have often faced difficulty ensuring well-developed wireless network infrastructure, accessing citizen-centric services, lack of well-established legislation for data and information practices [14], awareness and knowledge about the mobile applications available to access the specific services and fear of security and privacy through mobile-based transactions. Past research in the electronic government services literature has focused mainly on non m-government services, however, mobile communication for availing such services was largely ignored [1, 14]. Moreover, existing studies on m-government are mostly theoretical or targeted at users in developed economies [17]. Despite of the enormous opportunity of m-government implementation and use in India, there is a huge lack of research to understand why 
citizens of India do not use this technology to communicate with government and use its services. Realising this emerging research field and lack of research in this area in context of India, this study is an initial effort to fill in the existing gap in m-government research in the country through an exploratory qualitative research.

\section{Literature review}

A number of studies [e.g. 1, 14, 17, 23, 24] have examined the m-government adoption both in developed and developing economies. For example, Abdelghaffar and Magdy [1] introduced a conceptual model for youth's adoption of m-government services in the context of developing countries. Based on the data gathered from Egypt, the research found that perceived usefulness, compatibility, awareness, social influence and face-to-face interactions significantly contribute to the prediction of the intention to use m-government services. However, factors such as Internet experience, perceived ease of use, trust and personal connections were found non-significant on to the prediction of intention to use m-government. Abu-Shanab and Haidar [2] attempted to explore Jordanian citizens' perceptions toward using m-government. Their findings indicated the significant support for the influence of perceived usefulness, perceived ease of use, social influence, perceived responsiveness and perceived compatibility but not for perceived cost of service.

Al Thunibat et al. [6] found focus groups to engage users and accumulate their opinions as a valuable tool to use for the benefits of m-government project design, implementation and development. The research also found Malaysians to welcome the idea of getting services through mobile devices and are ready to adopt relatively new services. Al-Hadidi and Rezgui [7] reviewed the technical and non-technical barriers for m-government adoption and diffusion in the context of developed and developing countries. Based on their review, they found non-technical barriers such as lack of trust, privacy and security, language diversity, resistance to change, lack of management support, lack of data protection legislation etc. whereas technical barriers could include poor systems, lack of infrastructure such as wireless networks, security issues and mobile access devices and accessing software services. Al-Huan [8] explored the key issues faced by the Jordanian government toward fully utilizing the $\mathrm{m}$ government services. Based on the data gathered from egovernment officials, the findings indicated that the broader issues faced by the government are related to trust, public awareness, cost, lack of infrastructure and lack of enabling legal framework.

Al-khamayseh et al. [9] outlined the preliminary results from an online survey of experts toward understanding the success factors of m-government. These factors include privacy and security, infrastructure, user needs and preferences, quality and user-friendly applications, e-government acceptance and cost. Alsenaidy and Ahmad [10] reviewed the current state of m-government in Saudi Arabia and found that the concept of m-government is still in its early stage and there are certain challenges including trust issues and additional infrastructural cost that come to the way of successful implementation of m-government in the country. They also suggested that the government of Saudi Arabia should pay more attention toward introducing m-government in public sector services.

Cilingir and Kushchur [11] evaluated the m-government efforts in Turkey within a larger context of e-government. They found various effective examples of mobile government implementations even though the traditional egovernment coordination was yet to be realized. Ghyasi and Kuschu [12] presented a comparative analysis of trends within development framework and discussed implications for policy makers, government officials and information technology (IT) solution providers. They found that mobile technologies can provide more benefits to developing countries as they can bypass building all the heavy infrastructures, cost and time associated to develop the infrastructure to adopt wireless technologies. Hong and Tam [13] attempted to understand individual adoption of multipurpose information appliances using data collected on mobile data services. Their findings indicated that antecedents of multipurpose information appliance adoption decisions are different to those in the work place and dependent on the nature of the target technology and its usage context.

Hung et al. [14] identified the factors that influence user acceptance of m-government services. Based on the data collected from Taiwan, their findings revealed that perceived usefulness, perceived ease of use, trust, interactivity, external influence, self-efficacy and facilitating conditions were the critical factors determining the user acceptance of m-government services. Kalba [15] assessed the drivers for the mobile phone diffusion in emerging markets and found that mobile adoption in emerging markets is highly dynamic and still growing. They also acknowledged that there is a strong correlation between income level and mobile penetration in emerging markets. Based on a framework of m-government development, Lee et al. [16] presented a survey of m-government practices in leading countries of 
North America, Western Europe and East Asia. They summarized some salient benefits of m-government including increased productivity and effectiveness of government employees, improved delivery of the government information and services, reduced digital divide to name a few. Similarly, they highlighted the risk in terms of security and privacy, infrastructural development, lack of user readiness and information overload. Liu et al. [17] examined the interdependence among rural residents' demographic attributes, their access to and perceptions of $\mathrm{m}$ government and evaluates how their intention to use mgovernment is influenced by technology attributes, social factors and trust beliefs. Their results indicated that young males who live far away from a village center or market and possess some knowledge about recent government policies tend to have more positive insight of m-government and therefore become potential adopters of the service. They also found that perceived ease of use, near-term usefulness, longterm usefulness, integrity, benevolence, image and social influence significantly and positively influenced user's intention to use mobile government. Shareef et al. [18] addressed and hypothesized the factors contributing to the understanding of citizen's intention to adopt m-government services in India. The research found that perceived ease of use, security, relative advantage and empathy are significant factors for citizens to adopt m-government services. However, perceived reliability was found as a weak predictor for the behavioral intention to adopt m-government services. Singh [20] analyzed the pattern and rate of adoption of mobile phones in India. They predicted a rapid growth in the mobile density in India, which will have important implications for future plans for mobile operators, infrastructure providers, handset suppliers and vendors. They suggested that mobile operators ought to be prepared with their contingency plan to deploy and operate infrastructure such as customer care, billing, applications etc. sooner than they could have planned earlier. Susanto and Goodwin [21] identified the factors determining acceptance of citizens' acceptance of SMS based e-government services. The results indicated that there are fifteen perceptions toward using m-government services that impact citizens to use or reject the services. These include perceived ease of use, perceived efficiency in time and distance, perceived value for money, perceived usefulness, perceived responsiveness, perceived convenience, perceived relevance, quality and reliability of information, trust in the SMS technology, perceived risk to user privacy, perceived reliability of the mobile network and SMS-based system, trust in government and perceived quality of public services, perceived risk to money, perceived availability of device and infrastructure, perceived compatibility and perceived selfefficacy in using SMS. The authors argued that such systems should address all these belief factors in order to improve the adoption of SMS based e-government services. Tan et al. [22] examined whether factors like perceived usefulness, perceived ease of use and subjective norms influence users' intention to adopt m-learning system in Malaysia and found that all these factors positively influenced users' intention to adopt m-learning. Trimi and Sheng [23] argued that with the emergence and proliferation of wireless technology some of the technical impediments of m-government could be overcome. Wang [24] examined the antecedents and outcomes of perceived value in m-government continuance use in China. Based on the technology acceptance model and using the data gathered from 326 Chinese m-government users, the results indicated that perceived value is strongly influenced by mobility, perceived usefulness and security, which in turn can significantly influence satisfaction, trust in technology, trust in agent and trust and government.

\section{Research methodology}

We conducted an online survey using convenience sampling approach through selected group of friends from researchers' social network and close connections. The online survey (see Appendix-I) was created using Google drive comprising of a mix of demographic, close and some open-ended questions. The aim of the survey was to explore the respondents' usage of mobile for accessing government information and services in India. Participation in the survey was kept voluntary. The survey was conducted between the period of December 2017 until January 2018. We targeted 154 respondents and we received a response from 81 of them in about a month time. The responses provided by the respondents were treated in a strict confidence. We also ensured the anonymity of all participants taking part in the survey. We designate this research as exploratory because it is ongoing in nature and at the time of writing this paper, we could only gather a part of response that makes the basis for the analysis of data and present the exploratory findings of the research on that basis.

We asked respondents few open-ended questions related to what different things would they typically do by using mobile phones, how important a mobile phone is for them and what impact it has made in their personal and professional life since they started using them and whether they use social media for communicating or interacting with government. In addition, we also sought their opinion 
through some close-ended questions on [1-7] point Likert scale regarding how important do they think they are of enabling themselves to access government services via mobile phone and how important the availability, awareness, skills, literacy level, digital literacy level, cost of accessing government services, access to training for using a specific government service, trust of accessing government services, level of risk involved in accessing government services via mobile phone and the degree of anxiety while using mobile accessing services or doing transaction using mobile phones are for them. We have received some interesting results out of the analysis of data gathered from them, which will make the basis for presenting our next section on results.

\section{Results and discussion}

\subsection{Demographic characteristics}

The statistics (see Table 1) indicate that the largest 25.9\% respondents belong to the age-group of 25-29 years followed by $21 \%$ belonging to the age-group of $20-24$ years. The further $18.5 \%$ respondents are represented jointly by the age groups of $30-34$ and $40-44$ years. The survey results also found that $7.4 \%$ of respondents were in the age range of $35-$ 39 years whereas lowest $2.5 \%$ respondents shared the age range of under-19 as well as 50-54 years. This diversified distribution with almost two-third of the overall respondents falling in the age range of 20-34 years indicate that they are mid-age range people interested more toward Internet enabled mobile technology.

The age distribution shows that $35.8 \%$ of the total respondents were female whereas remaining $64.2 \%$ were male. This reflects the general trend in the technology sector where females are traditionally under-represented. The respondents' occupation and the related analyses indicate that the largest $46.9 \%$ respondents are students whereas $22.2 \%$ of the total respondents are employed each with private- as well as public-sector and only $4.9 \%$ are selfemployed. This clearly indicates that the majority of students and working-class people can afford smartphone and they are probably the right people to respond to and share $\mathrm{m}$ government adoption related questions in Indian context.

Moreover, the analysis of data also indicated that the largest $44.4 \%$ respondents have a postgraduate degree, 47 out of 81 respondents have an experience of 10 years or more of using mobile phones, the most of them can read and write English and Hindi fluently and possess smartphone and more than anything else they all spend at least an hour of their everyday time on their phones. This shows that they do not only have a good knowledge about accessing and using the system, but they also use them on the regular basis.

Table 1. Demographic characteristics

\begin{tabular}{|l|c|}
\hline Characteristics & $\%$ \\
\hline Gender & $64.2 \%$ \\
\hline Male & $35.8 \%$ \\
\hline Female & $2.5 \%$ \\
\hline Age Group (in Years) \\
\hline Under 19 & $21.0 \%$ \\
\hline $20-24$ & $25.9 \%$ \\
\hline $25-29$ & $18.5 \%$ \\
\hline $30-34$ & $2.5 \%$ \\
\hline $35-49$ & $18.5 \%$ \\
\hline $40-44$ & $8.6 \%$ \\
\hline $45-49$ & $2.5 \%$ \\
\hline $50-54$ & $46.9 \%$ \\
\hline Occupation & $22.2 \%$ \\
\hline Student & $22.2 \%$ \\
\hline Employee-Private sector & $4.9 \%$ \\
\hline Employee-Public sector & $3.8 \%$ \\
\hline Self-employed & $44.4 \%$ \\
\hline Others & $34.6 \%$ \\
\hline Education & $16.0 \%$ \\
\hline Postgraduate taught & $5.0 \%$ \\
\hline Postgraduate research & \\
\hline Graduate & \\
\hline Others & \\
\hline \multicolumn{2}{|l|}{} \\
\hline
\end{tabular}

\subsection{M-Government related questions}

We asked respondents both open as well as close ended questions relating to use of smartphone to access and transact government information and services. In response to an open-ended question on what different things (e.g. activities or services including buying product online, searching for information online or accessing government services) would they do on a typical day using their mobile phones, most of them said that they would look for information, browse through social media sites and access emails and buying products online (such as railway and airline reservation, hotel booking, online shopping, online banking etc.) whereas only four of them explicitly acknowledged that they also accessed government services through their mobiles. This clearly indicates that even though people are using smartphone on their day-to-day use, majority of them do not necessarily spend their time accessing government information or transacting 
government services. Moreover, a very few of them also use their mobile phones for Google maps, online dictionary, gaming, matrimonial services and entertainment purposes.

We further asked them whether they use (or have you ever used) social media for communicating and interacting with (local/state/national) government? If so, then please give an example (if possible) of their communication and/or interaction with government that they have done in the past using social media? The analysis of data on this question indicates that 47 (i.e. more than $50 \%$ of overall respondents) out of 81 respondents have not yet used social media to interact with the government at any level. The other respondents who interacted with government revealed that they used social media just to communicate their local and personal issues to ministry of human resource development (HRD) (e.g. to raise concerns about lack of teaching staff in a college), railway, foreign affairs (e.g. complaint for not getting a passport for a baby born in Istanbul), transport (e.g. for constructing a damaged road), electricity (e.g. to ensure the regular supply of electricity), minority ministry, water, income tax (e.g. to file complaint against few authorities), prime minister office, local police, ministry of horticulture etc. But, some of them also acknowledged that they did not get any response back from the government or have not mentioned about the outcome of their communication. Most of the respondents used social media mainly for connecting with friends and family or for networking purposes.

One respondent said "direct interaction with the government has been quite rare in recent time, perhaps because I had no need for the same and also because I belong to the government and able to get my work done without having to go through social media channel. However, I am aware that government is quite accessible and responsive on social media". This narrative also reflects that public-sector employees may tend to think because they already work for government there is no need for them to interact with government using social media channels.

We further asked respondents 10 close-ended 7-point Likert scale questions where ' 1 ' represents 'not at all important', '2' represents 'low important', ' 3 ' represents 'slightly important', '4' represents 'neutral', '5' represents 'moderately important', ' 6 ' represents 'very important' and '7' represents 'extremely important'. The first question was how important do they think of government services via mobile phone where availability (possessions) of phones is suitable for accessing government services? In response to this question, the majority of respondents think positively with largest $37 \%$ consider this as very important, $29.6 \%$ as moderately important and $13.6 \%$ as extremely important whereas overall only $8.6 \%$ of them consider this as not at all important to slightly important. The prior research has talked about a number of factors for adoption and usage of $\mathrm{m}$ government but none of them have talked about availability. This is possibly because the research would have assumed that respondents would answer the questions considering resources available to them. But, this is a very pertinent question in a developing country like India where people would access and use m-government only when they have mobile phones to use them. But, this response is not quite in synchronization with the open-ended question where despite having access to the smartphones, respondents hardly used them for m-government related information and services. In response to the question that asks about awareness of what various government services are available through mobile phone. The respondents again responded the question positively with highest $38.3 \%$ of them think that it is very important and $21 \%$ consider it as extremely important whereas other $25.9 \%$ consider awareness as moderately important. However, only $4.9 \%$ consider awareness as a low important aspect. This finding is supported by the research of Al-Huan [8] and Abdelghaffar and Magdy [1], who also supported awareness about m-government as one of the key factors for it acceptance.

The third question is related to significance of skills required for accessing m-government services. Like awareness, skills to use and access the government information through mobile phones were also considered as important aspect of m-government services. The highest 39.5\% respondents considered this as very important whereas the second largest number of respondents also considered skills as moderately important factor (24.7\%). Only $13.6 \%$ of overall respondents considered skills as slightly to not at all important aspect in accessing government information.

Next, we present the response relating to a question on importance of literacy level (i.e. ability to read and write in language used in mobile services) whereas the subsequent response is related to the importance of digital literacy (i.e. ability to use variety of electronic devices and services) to access the m-government services.

The response to both these questions were similar in terms of majority of respondents accepting them as extremely, very or moderately important factor. However, only a fraction of overall respondents did not quite consider them as important factors.

The next question asked to the respondents was on cost of accessing government services charged by mobile network operator. Although the highest (i.e. 32.1\%) number of respondents considered this as a very important aspect, 14 of the overall respondents also considered this as a factor of low importance and 15 respondents remained neutral as well. 
This indicates that overall cost is surely a crucial factor but for accessing the m-government services, this is not that important in the opinion of some other respondents as they bear the cost of using Internet in their mobile phones no matter whether they use it for m-government services or not. Some of the prior literature [e.g. 8, 9] have supported cost of services as a significant factor for the successful acceptance and use of m-government services whereas Abu-Shanab and Haidar [2] found cost as non-significant as far as Jordanian citizens' perception to use m-government services are concerned. Abu-Shanab and Haidar [2] argued that even though Jordan is a developing country, Jordanians are not quite keen on cost when they perceive m-government as easy to use and useful service to be used. But, we argue that the cost of service does matter in a developing economy like India no matter how much easy to use and useful mgovernment interface is provided to users.

The response for the next question is related to access of training for using specific m-government services. The highest $29.6 \%$ of the overall respondents think this as a very important factor whereas the next highest $23.5 \%$ considered this as moderately important factor. In addition, $17.3 \%$ remained undecided in response to this question whereas $11.1 \%$ considered this as an extremely important factor. So, the respondents' opinions are relatively diverging, and this is possibly because of the uncertainty about the need for training for those whose response (i.e. $23.5+7.4+17.3=48.2 \%$ ) was in terms of moderately or slightly important and those who remained undecided about it. None of the existing literature has reinforced the need for any training for accessing m-government services.

The further response was about a question asked on trust in accessing government services via mobile phones. Majority of respondents either considered trust as extremely important (i.e. 27.2\%), very important (i.e. $46.9 \%$ ) or moderately important (i.e. 11.1\%) aspects of accessing government services through mobile phones. This clearly indicates that trust is a very crucial factor for accessing and use of mobile phones. A number of prior studies [7, 8, 10, $14,17,21,24]$ have also acknowledged trust as a crucial factor for acceptance and use of m-government services.

Similar to trust, majority of respondents (i.e. $27.2 \%$ considered this as very important whereas $24.7 \%$ as extremely important issue) also considered risk as equally important issue as far as accessing government services through mobile phones are concerned. Prior studies [e.g. 16, 21] have also considered risk to privacy and security as a threat for mobile users' identity and transaction.

The response to a final question is on anxiety while using mobile for accessing or transacting government services.
The outcome of this question is very similar to the one experience when questions related to risk were asked. 27.2\% of the overall respondents, similar to risk related question, considered anxiety as a very important issue followed by $23.5 \%$ respondents who considered this as extremely important aspect as far as accessing government services through mobile phones are concerned. Only a small percentage of respondents (i.e. 19.8\%) considered anxiety at the slightly important to not at all important category.

Breach of trust to users can result in greater risk of anxiety. The findings indicate that risk is an important issue for mgovernment users and this higher risk of operating mgovernment services can further trigger anxiety and hence has been considered as an equally important issue like trust and risk [19].

\section{Conclusion}

This paper has presented the results of a qualitative study around the questions of awareness, acceptance and use of $\mathrm{m}$ government services. The findings of this research indicate that even though the users are well aware of m-government services and possess smartphone, only a handful of them use their mobiles for accessing government services. The further analysis also indicates that although not many users directly interact with government through mobile phones, they largely used social media platforms such as Facebook and Twitter to interact with the government and convey their issues to the various ministries. However, the response rate from government to the issues raised by citizens are very negligible. The findings clearly show that social media is a prominent intermediary between government and citizens as most of the users tend to follow one or the other social media platform. In response to the close-ended 7-point Likert scale questions asked on 10 different issues including availability of mobile phones, awareness about the government services, skills required for accessing government services, literacy and digital literacy level, cost of accessing government services, access to training for using a specific service, trust, risk and anxiety and their relevance with regard to access and use of government services using mobile phones, majority of the respondents considered them in the category of extremely, most or moderately important issues.

\subsection{Recommendations}

Despite the growing upsurge of Internet users - including 314 million mobile Internet users - and being the world's second largest smartphone market $[4,5], \mathrm{m}$-government in India still seems to be at its early stage and needs further 
research to improve the effectiveness of m-government services to attain the wide public attention and acceptance at large. Our findings indicated that there is a lack of public awareness about the availability of government services through mobile phones and respondents have also acknowledged this as an important factor for accessibility and use of such services through mobile phones. The government should use its various media channels (e.g. print media, radios, televisions and social media platforms) to advertise such services and pronounce the potential benefits that the citizens would be able to gain by using such services. In addition, the government should also streamline its essential services through mobile phones and encourage its citizens to avail them through mobile phones. As far as skills of accessing government services through mobile is concerned, the government can provide short videos or visuals and tutorial or training that clearly demonstrates the steps through which the information can be accessed, or services could be attained. Furthermore, literacy and digital literacy is an issue in a country of massive population like India where illiteracy rate is more than $25-30 \%$ and digital literacy is almost nonexistent among more than $90 \%$ population in the country. In a country like India where more than $70 \%$ population lives in villages with a very high literacy rate and almost negligible digital literacy rate, there is an enormous requirement before the governments at both state and central level to light up the rural communities and to help them conquer their challenges of both literacy and digital literacy. This could be achieved in a bare minimal time only when the governments' initiatives to educate illiterate people are instigated by killing two birds (i.e. literacy and digital literacy) by one stone i.e. educating them using digital devices. The national digital literacy mission programme in India is a dynamic and integrated platform of digital literacy awareness and education to help rural communities to take the lead in the digital economy with a pledge to digitally literate at least one adult from each of 147 million rural households in India [5]. The government of India should work along with such non-government organisations to ensure that such challenges can be overcome in the optimal possible time in the future for India to ride a wagon-wheel of digital development in the time to come. If India has to diffuse the Internet enabled mobile phones to the grassroots, the government should also think about regulating policies and directing the mobile network providers to maintain a decent cost for accessing Internet to allow the common masses to use them at affordable expenses. Finally, trust, risk and anxiety are the issues that are faced while accessing the government services through mobiles even in developed economy. For the country like
India where the m-government has been in initial phases, such issues cannot be ignored. The governments should first try to build its integrity and trustworthiness among citizens on all fronts to rely them and their initiatives at the very basic level. At the same time, governments must also address risks to privacy and security. For example, governments can formulate guidelines concerning the release of public information that may contain personal or sensitive data.

\subsection{Limitations and future research}

First, this research is based on the online survey of only 81 well-educated and digitally literate respondents and this is the reason why we have considered it as an exploratory research. Therefore, the researchers should take caution to generalize the findings of this research to a wider population. Second, this is a qualitative research and even the responses for the close-ended questions have not been analysed using quantitative approach. Due to small sample size and limited space, we have only presented the overall views of respondents for about 10 key issues around accessing government services through mobile. The future research will gather more data to develop a research framework around the selected factors and validate it with relatively large sample. Third, the current work is based on the data gathered using convenience sampling technique and hence would raise concerns relating to biases of the data. The future work will gather data using random sampling technique both through manual and online survey approaches. Fourth, although we have largely analysed the factors influencing m-government adoption in literature, it is not a validation of a proposed research model using survey data. The future research should provide the influence of factors on m-government adoption by collecting primary data on the items related to various constructs $[25,26,27$, $28,29,30,31,32,33,34,35,36]$. Finally, this research does not examine the barriers, critical success factors and the proposed framework to understand their interrelationships. The future research can use interpretive structural modelling, analytic hierarchy process, interpretive ranking process etc. to understand the interrelationships and ranking of the key factors of m-government services [37, 38, 39, 40, 41, 42, 43].

\section{Acknowledgments}

This is an original work undertaken by the researchers based on the views of respondents gathered through the online survey consisting of mix of demographic, open- and closeended questions on users' awareness, acceptance and use of mobile phones for accessing government services in India. 


\section{References}

[1] H. Abdelghaffar, and Y. Magdy, The adoption of mobile government services in developing countries: The case of Egypt. International Journal of Information, 2(4), 333341, 2012.

[2] E. Abu-Shanab, and S. Haider, Major factors influencing the adoption of m-government in Jordan. Electronic Government, an International Journal, 11(4), 223-240, 2015.

[3] I. Lunden, 6.1B Smartphone Users Globally By 2020, Overtaking Basic Fixed Phone Subscriptions. Accessed from https://techcrunch.com/ 2015/06/02/6-1bsmartphone-users-globally-by-2020-overtaking-basicfixed-phone-subscriptions, 2015

[4] H. Mallya, With 3rd largest smartphone market in the world, India to reach 314 million mobile internet users by 2017. Accessed from https://yourstory.com/2015/07/ mobile-internet-report-2015, on 21st September 2017, 2015.

[5] DEF, Digital Empowerment Foundation. Accessed from the web: http://defindia.org/national-digital-literacymission on 21st September 2017, 2017.

[6] A. Al Thunibat, N.A.M. Zin, and N. Sahari, Identifying user requirements of mobile government services in Malaysia using focus group method. Journal of eGovernment Studies and Best Practices, 1-14, 2011.

[7] A. Al-Hadidi, and Y. Rezgui, Adoption and diffusion of mgovernment: Challenges and future directions for research. Collaborative Networks for a Sustainable World, 88-94, 2010.

[8] O. Al-Huan, Toward the utilization of m-Government services in developing countries: A qualitative investigation. International Journal of Business and Social Science, 3(5), 155-160, 2012.

[9] S. Al-khamayseh, E. Lawrence, and A. Zmijewska, Towards understanding success factors in interactive mobile government. In the Proceedings of Euro mGov, 2006.

[10] A. Alsenaidy, and T.A.U.S.E.E.F. Ahmad, A review of current state m-government in Saudi Arabia. Global Engineers \& Technologists Review, 2(5), 5-8, 2012.

[11] D. Cilingir, and I. Kushchu, E-government and mgovernment: Concurrent leaps by Turkey. In European Conference on E-Government (ECEG 2004), Trinity College, Dublin, June (pp. 17-18), 2004.

[12] A.F. Ghyasi, and I. Kushchu, Uses of mobile government in developing countries. Mobile Government Lab (mGovLab. Org), 2004.

[13] S.J. Hong, and K.Y. Tam, Understanding the adoption of multipurpose information appliances: The case of mobile data services. Information systems research, 17(2), 162179,2006

[14] S.Y. Hung, C.M. Chang, and S.R. Kuo, User acceptance of mobile e-government services: An empirical study. Government Information Quarterly, 30(1), 33-44, 2013.

[15] K. Kalba, The adoption of mobile phones in emerging markets: Global diffusion and the rural challenge. International journal of Communication, 2 , 631-661, 2008.

[16] S.M. Lee, X. Tan, and S. Trimi, M-government, from rhetoric to reality: learning from leading countries. Electronic Government, an International Journal, 3(2), 113-126, 2006.

[17] Y. Liu, H. Li, V. Kostakos, J. Goncalves, S. Hosio, and F. $\mathrm{Hu}$, An empirical investigation of mobile government adoption in rural China: A case study in Zhejiang province. Government Information Quarterly, 31(3), 432442, 2014.

[18] M.A. Shareef, N. Archer, and Y.K. Dwivedi, Examining adoption behavior of mobile government. Journal of Computer Information Systems, 53(2), 39-49, 2012.

[19] S.K. Sharma, A. Al-Badi, N.P. Rana, and L. Al-Azizi, Mobile applications in government services (mG-App) from user's perspectives: A predictive modelling approach. Government Information Quarterly, DOI: 10.1016/j.giq.2018.07.002, 2018.

[20] S.K. Singh, The diffusion of mobile phones in India. Telecommunications Policy, 32(9), 642-651, 2008.

[21] T.D. Susanto, and R. Goodwin, Factors influencing citizen adoption of SMS-Based e-Government Services. Electronic Journal of E-Government, 8(1), 5571, 2010.

[22] G.W.H. Tan, K.B. Ooi, J.J. Sim, and K. Phusavat, Determinants of mobile learning adoption: An empirical analysis. Journal of Computer Information Systems, 52(3), 82-91, 2012

[23] S. Trimi, and H. Sheng, Emerging trends in Mgovernment. Communications of the ACM, 51(5), 53-58, 2008.

[24] C. Wang, Antecedents and consequences of perceived value in Mobile Government continuance use: An empirical research in China. Computers in Human Behavior, 34, 140-147, 2014.

[25] N.P. Rana, Y.K. Dwivedi, B. Lal, M.D. Williams, and M. Clement, Citizens' Adoption of an Electronic Government System: Toward a Unified View. Information Systems Frontiers, 19(3), 549-568, 2017.

[26] Y.K. Dwivedi, N.P. Rana, M. Janssen, B. Lal, M.D. Williams, and M. Clement, An empirical validation of a unified model of electronic government adoption (UMEGA). Government Information Quarterly, 34(2), 211-230, 2017.

[27] N.P. Rana, Y.K. Dwivedi, M.D. Williams, and V. Weerakkody, Adoption of Online Public Grievance Redressal System in India: Toward Developing a Unified View. Computers in Human Behavior, 59, 265-282, 2016.

[28] A.A. Alalwan, Y.K. Dwivedi, N.P. Rana, and M.D. Williams, Consumer adoption of mobile banking in Jordan: Examining the role of usefulness, ease of use, perceived risk and self-efficacy. Journal of Enterprise Information Management, 29(1), 118-139, 2016.

[29] A.A. Alalwan, Y.K. Dwivedi, N.P. Rana, and A.C. Simintiras, Jordanian Consumers' Adoption of Telebanking: Influence of Perceived Usefulness, Trust and Self-Efficacy. International Journal of Bank Marketing, 34(5), 690-709, 2016.

[30] M. Alryalat, N.P. Rana, and Y.K. Dwivedi, Citizen's adoption of an e-government system: Validating the 
extended theory of reasoned action (TRA). International Journal of Electronic Government Research, 11(4), 1-23, 2015.

[31] N.P. Rana, and Y.K. Dwivedi, Citizen's adoption of an egovernment system: Validating extended social cognitive theory (SCT). Government Information Quarterly, 32(2), 172-181, 2015.

[32] A.A. Alalwan, Y.K. Dwivedi, N.P. Rana, B. Lal, and M.D. Williams, Consumer Adoption of Internet Banking in Jordan: Examining the Role of Hedonic Motivation, Habit, Self-Efficacy and Trust. Journal of Financial Services Management, 20(2), 145-157, 2015.

[33] N.P. Rana, Y.K. Dwivedi, M.D. Williams, and V. Weerakkody, Investigating Success of an E-Government Initiative: Validation of an Integrated IS Success Model. Information Systems Frontiers, 17(1), 127-142, 2015.

[34] N.P. Rana, Y.K. Dwivedi, M.D. Williams, and B. Lal, Examining the Success of the Online Public Grievance Redressal Systems: An Extension of the IS Success Model. Information Systems Management, 32(1), 39-59, 2015.

[35] N.P. Rana, Y.K. Dwivedi, and M.D. Williams, Evaluating the Validity of IS Success Models for E-Government Research: An Empirical Test and Integrated Model. International Journal of Electronic Government Research, 9(3), 1-22, 2013.

[36] A.A. Alalwan, Y.K. Dwivedi, and N.P. Rana, R.S. Algharabat, Examining Factors Influencing Jordanian Customers' Intentions and Adoption of Internet Banking: Extending UTAUT2 with Risk. Journal of Retailing and Consumer Services, 40, 125-138, 2018.

[37] H. Al-Muftah, V. Weerakkody, N.P. Rana, U. Sivarajah, and Z. Irani, E-diplomacy Implementation: Exploring Causal Relationships Using Interpretive Structural Modelling. Government Information Quarterly, DOI: 10.1016/j.giq.2018.03.002, 2018

[38] S.K. Mangla, N. Rich, S. Luthra, D. Kumar, N.P. Rana, and Y.K. Dwivedi, A Combined ISM-Fuzzy DEMATEL Based Framework for Implementing Sustainable Initiatives in Agri-food Supply Chains. International Journal of Production Economics, DOI: 10.1016/j.ijpe.2018.07.012, 2018.

[39] N.P. Rana, S. Luthra, S. Mangla, R. Islam, S. Roderick, and Y.K. Dwivedi, Identifying and Prioritising Barriers to the Development of Smart Cities in Indian Context. Information Systems Frontiers, DOI: 10.1007/s10796018-9873-4, 1-23, 2018.

[40] N. Mishra, A. Singh, N.P. Rana, and Y.K. Dwivedi, Interpretive Structural Modelling and Fuzzy MICMAC Approaches for Customer Centric Beef Supply Chain: Application of a Big Data Technique. Production Planning \& Control, 28(11-12), 945-963, 2017.

[41] M. Janssen, N.P. Rana, E. Slade, E., and Y.K. Dwivedi, Trustworthiness of Digital Government Services: Deriving a comprehensive theory through Interpretive Structural Modelling. Public Management Review, 20(5), 647-671, 2018.

[42] D.L. Hughes, Y.K. Dwivedi, and N.P. Rana, Mapping IS Failure Factors on PRINCE2 ${ }^{\circledR}$ Stages: An Application of
Interpretive Ranking Process (IRP). Production Planning \& Control, 28(9), 776-790, 2017.

[43] D.L. Hughes, Y.K. Dwivedi, N.P. Rana, and A.C. Simintiras, Information Systems Project Failure - Analysis of Causal Links using Interpretive Structural Modelling. Production Planning \& Control, 27(16), 1313-1333., 2016.

\section{[A] APPENDIX-I}

The aim of this survey is "to explore mobile and social media usage by Indian citizens". The questionnaire consists of a number of questions that should take approximately 15 minutes to complete. Participation is voluntary, and all responses will be kept anonymous. Please be assured that the answers you provide will be treated in a strict confidence and the anonymity of all participants will be secured in this study. Upon the completion of study, all data will be destroyed. Any individual data collected in this survey will not be disclosed to any third party. Your answer will always be kept confidential and no one will have access to these except for the researcher.

We would like to take this opportunity to thank you for your time and patience in completing this questionnaire!

A.1 Demographic questions

Q1: What is your age?

Q2: What is your Gender?

Q3: What is your highest level of education?

Q4: What is your current occupation?

Q5: Can you read and write in Hindi?

Q6: Can you read and write in English?

Q7: In which other languages you can read and write?

A.2 Open-ended questions

Q8: Since how long you have been using mobile phones?

Q9: What types (basic or smartphone) of mobile phone you currently own?

Q10: Do you access (or connect with) internet using your mobile phone?

Q11: How much time in total every day you spent on mobile phone?

Q12: On a typical day (please remember within last one month) what different things (activities or services including buying product online, looking information online or accessing government services) you do by using your mobile phone?

Q13: Do you use (or have you ever used) social media for communicating and interacting with (local/state/national) government? If so, then please give an example (if possible) of your communication and/or interaction with government that you have done in past using social media.

A.3 Close-ended questions

Please rate (by highlighting and/or underlining correct option) each of the following factors listed below on a 1-7 points scale in terms of how important you think they for enabling you to access government services via mobile phone where ' 1 ' represents 'not at all important', '2' represents 'low important', '3' represents 'slightly important', '4' represents 'neutral', '5' represents 'moderately important', '6' represents 'very important' and '7' represents 'extremely important'.

Q14: Availability (possessions) of phones suitable for accessing government services via mobile 
Q15: Awareness about what government services are available via mobile phones

Q16. Skills required for accessing government services via mobile phones

Q17. Literacy level (Ability to read and write in language used in mobile services)

Q18. Digital literacy level (Ability to use variety of electronic devices and services)

Q19. Cost of accessing government services (charged by mobile network operators)

Q20. Access to training for using a specific mobile government service

Q21. Trust in accessing government services via mobile phone

Q22. Risk involve in accessing government services via mobile phone

Q23. Anxiety when using mobile accessing services or doing transaction using mobile phones 